\title{
A Time Course Study and Competition between Rhizobia-Affecting Nodulation in Two Soybean Genotypes
}

\author{
H.K. Abd El-Maksoud and H.H. Keyser \\ Agricultural Microbiology Department, National Research \\ Centre, Giza, Egypt.
}

\begin{abstract}
Areenhouse experiment was conducted to evaluate the time A course of nodulation and completion between strains USDA 123 and CB 1809 on Williams soybean and on P1 377578 (\#671). This P1 has been shown to restrict nodulation and competition of USDA 123. The study was performed using vermiculite and fine sandy loam soil as growth media. Nodulation and competition in both medium were evaluated at $4,6,8$ and 10 weeks. Three additional treatments included delayed inoculation of CB 1809 at 1, 2 and 4 weeks after inoculation the soil with USDA 123 were also performed. Averaged over the dates, strain USDA 123 produced 35 and $37 \%$, respectively of the nodule mass and number on P1 377578 as compared to CB1809. In competition for nodulation in vermiculite, USDA 123 formed $43,80,62$ and $64 \%$ of the nodules on Williams at 4, 6, 8 and 10 weeks, respectively, while only formed $0,16,9$ and $16 \%$ of the nodule on P1 \# 671. In soil, USDA 123 formed $95 \%$ or more of the nodule on Williams through 10 weeks, while it formed $29 \%$ or less of the nodules on P1 \# 671. In the delayed inoculation treatments a maximum of $14 \%$ of the nodules on Williams were formed by $\mathrm{CB}$ 1809 , whereas on P1 \# 671 a ratio of $89 \%$ or more were colonized by the same strain. The marked influence of the host on competition and affinity to nodulate with certain strain is demonstrated in this study.
\end{abstract}

Keywords: Soybean, Time course, Host`s mechanism, Competition.

The first step in the development of the root nodule symbiosis in the mutual recognition by the two partners a process which is rather specific. However, it is not necessary that the highly infective strain could be the highly effective one to fix copious nitrogen for plant requirements. Thus, successful nodulation and nitrogen fixation by legumes inoculated with Rhizobium strains depend on genetic and environmental factors. Once introduced, Rhizobium bacteria must multiply in the rhizosphere and infect their host plant to initiate the symbiotic process (Swelim et al., 1996). Success depends on competitiveness, ability to survive in the soil and compatibility of the host (Dowling and Broughton, 1986). Many effective strains have been reported to poor competitors and may consequently form very few nodules in the presence of ineffective strains 
(Franco and Vincent, 1976 and Trinick, 1982). Keyser and Li (1992) mentioned that one of the major problems in nodulation technology with soybean is the establishment of an introduced inoculums strain of B. japonicum of the nodules of soybean grown in soil which contain indigenous population of bradyrhizobia. Thus, when the indigenous strains dominate the nodules, response to inoculation is not observed. In some instances, serogroup USDA 123 is poorly competitive in occupying nodules under certain conditions, these conditions seemed to be related to the host mechanism of nodule regulation (Olsson et al., 1989). Kosslak et al. (1983) reported that many factors of both the microsymbiote and the host play important roles in determining which strain succeeds in occupying the majority of the nodules. Furthermore, other studies have indicated that the host plant can play an important role in selecting the successful strain (Diatloff and Brockwell, 1976 and May \& Bohlool, 1983). Other workers suggested that the early events in infection and nodulation are important in competition among Bradyrhizobium japonicum strains (Kosslak et al., 1983 and Heron \& Pueppke, 1987). In their study, Cregan and Keyser (1986) demonstrated that, variation in the time required to form nodules by particular strains of Rhizobium may play a key role in determining competitiveness among genotypes of soybean, they also added that indigenous strains could be restricted by the host plant and nodulation could be done by the preferable rhizobial strain maintained in the interoduced favourable inoculum. Bauer (1981) reported that the host plant respond rapidly to the challenge by Rhizobium, within two or four hours. It appears that the host plant can distinguish the fate of an infection at a very early stage with respect to its potential in establishing the symbiotic nitrogen-fixing state furthermore, the host plant appears to control not only the mode of infection but also the morphology and intracellular organization of the infected cell (Verma and Nadler, 1987). However, Keyser and Li (1992) recommended that the provision of superior strains for use in inoculants remains the primary applied contribution from the field of BNF. The main objectives of this study are to compare the time course of nodulation and competition among two strains of bradyrhizobia and also to evaluate the effect of delayed inoculation with an effective strain on $\mathrm{N}_{2}$ fixation in vermiculite and sandy soil.

\section{Material and Methods}

A greenhouse pot experiment was conducted on soybean (Glycine max L. Merill) cultivar Williams-82 and the introduction P1 377578 "671" using two inocula strains USDA 123 "Pm" and a competitor one CB 1809 "E" as effective strain. The experiment was performed in sterile vermiculite $\left(280 \mathrm{~g} \mathrm{pot}^{-1}\right)$. A number of 64 and 92 white plastic pots $7{ }^{-}$were used for vermiculite and soil growth media, respectively. The pots were soaked overnight in $10 \%$ of Rocal as a sanitizing agent and then thoroughly rinsed with tap water. A randomized complete block design was used that consisted of a split plot arrangement of treatments. Whole plots (pots) were inoculation treatments:

- Uninoculated control "UC".

- Strain USDA 123 premix "PM".

- highly effective strain CB 1809 "E".

Egypt. J. Soil Sci. 54, No. 3 (2014) 
- 123 premix + CB 1809 "Pm + E”.

Subplots were soybean genotypes Williams and P1 377578 (\#671). Each treatment was harvested at $28,42,56$, and 70 days after planting (DAP). In soil, additional inoculation treatments were performed, 123 premix followed by delayed inoculation of CB 1809 applied either at 7, 14 and 28 DAP. Plants were harvested 6 weeks after application of the delayed inoculation. Four pots were used as replicates. Seeds were surface sterilized for $10 \mathrm{~min}$. in $6 \%$ calcium hypochlorite, washed exhaustively with sterile water and pre-germinated for $48 \mathrm{hr}$. on soft agar plates, $7.5 \mathrm{~g}$ agar liter ${ }^{-1}$, and incubated at $28{ }^{\circ} \mathrm{C}$. Two pregerminated seeds of both soybean genotypes were sown per hole (4 holes/pot).

W

W

cultivated pot

Rhizobial inoculation was done as following: a volume of $0.25 \mathrm{ml}$ of the original culture USDA $123\left(5.6 \times 10^{8} \mathrm{cell} / \mathrm{ml}\right)$ were added to each pot after dilution with $100 \mathrm{ml}$ of sterilized solution containing $\mathrm{NaCl}, \mathrm{MgSO}_{4}$ and $\mathrm{K}_{2} \mathrm{HPO}_{4}$ (Broughton and Delworth, 1971) to obtain approximately initial count of $1 \times 10^{5}$ cell/g soil for premix treatment. The vermiculite Pm treatment treated with the same inoculum using different volume to get equal dense of rhizobial inoculums that mixed very well with soil and/or vermiculite before pot packing. For E treatment, $10 \mathrm{ml}$ of CB 1809 culture added to $90 \mathrm{ml}$ of yeast extract manitol broth to obtain a population of $1 \times 10^{8} / \mathrm{ml}$, then $1 \mathrm{ml}$ of the prepared inoculums was used for inoculation of each hole. Soil inoculation treatment was performed using an equal volume of culture CB 1809 for inoculation the pots pretreated with USDA 123 after 1,2 and 4 weeks of inoculation date, then $50 \mathrm{ml}$ of sterilized water were splashed on each hole containing two plants. After sowing the seeds, the pots upper surface was covered with sterilized gravels. Plants were thinned one week after to one plant per hole. Irrigation was done through the bottom of pots (into the tray at the bottom) wherever they need with $\mathrm{N}$ free nutrient solution through the week days. On the week end days tap water was used for watering to prevent salt accumulation (Somasegaran and Hoben, 1985). For each treatment 100 nodules were picked and analyzed for rhizobial strain occupancy by immunefluorescence "FA" with strain - specific fluorescent antibodies (Bohlool and Schmidt, 1980).

Measurements: nodule numbers and weight, top dry weight, top $\% \mathrm{~N}$, top total $\mathrm{N}$ and nodule typing percentage.

\section{Results and Discussion}


Top dry weight, nodule number and nodule dry weight per plant are shown in Table 1. In respect to top weight, the control treatment UC showed that soybean genotype Williams and / or the introduced one "671" achieved fairly similar growth when nitrogen was limited in the soil treatment. On the other hand, inoculation with the proper rhizobial strain enhances the $\mathrm{N}_{2}$ fixation process resulted in increasing biomass metabolism by plant. So, the interaction between strain 123 and Williams revealed top growth four times as much as 671 at 70 DAP. On the other hand, the interrelationship between the host 671 and the symbiont CB 1809 did much better than with strain 123 however, Williams did not, that is why strain CB 1809 was chosen as an inoculum strain because of its superior performance in a previous field trail in similar soil conducted by Cregan and Keyser (1986). The competition treatment $(\mathrm{Pm}+\mathrm{E})$ showed a similar pattern when Williams was with strain 123 alone and P1 671 with CB 1809 alone. This was also found with the delayed inoculation treatments.

TABLE 1. Top dry weight, nodule number and nodule dry weight/plant of soybean.

\begin{tabular}{|c|c|c|c|c|c|c|c|c|c|c|c|c|c|}
\hline \multirow[t]{3}{*}{ Treatment } & \multirow{3}{*}{$\begin{array}{l}\text { Time of } \\
\text { sampling }\end{array}$} & \multicolumn{4}{|c|}{ Top $0 . \mathrm{W} \mathrm{g} /$ plant } & \multicolumn{4}{|c|}{ Nodule numbers } & \multicolumn{4}{|c|}{ Nodule D.W. mg/plant } \\
\hline & & \multicolumn{2}{|c|}{ Soll } & \multicolumn{2}{|c|}{ Vermiculite } & \multicolumn{2}{|c|}{ Soil } & \multicolumn{2}{|c|}{ Vermiculite } & \multicolumn{2}{|c|}{ Soil } & \multicolumn{2}{|c|}{ Vermiculite } \\
\hline & & W & 671 & W & 671 & W & 671 & W & 671 & W & 671 & $w$ & 671 \\
\hline$U C$ & \multirow{4}{*}{4 wks } & 1.51 & 1.51 & 0.39 & 0.39 & 0 & 0 & 0 & 0 & 0 & 0 & 0 & 0 \\
\hline $\mathrm{Pm}^{\alpha} 123^{n}$ & & 1.36 & 1.44 & 0.75 & 0.39 & 61 & 0 & 36 & 16 & 56 & 0 & 94 & 27 \\
\hline$E^{\prime \prime C}\left(81809^{\prime \prime}\right.$ & & 1.39 & 1.32 & 0.78 & 0.72 & 8 & 3 & 31 & 25 & 40 & 14 & 73 & 53 \\
\hline$P m+E$ & & 1.48 & 1.40 & 0.78 & 0.66 & 74 & 11 & 29 & 16 & 71 & 12 & 79 & 56 \\
\hline$U C$ & \multirow{4}{*}{6 wks } & 3.82 & 3.74 & 0.62 & 0.50 & 0 & 0 & 0 & 0 & 0 & 0 & 0 & 0 \\
\hline $\mathrm{Pm}$ & & 6.82 & 3.29 & 3.69 & 0.76 & 125 & 19 & 82 & 23 & 359 & 54 & 343 & 84 \\
\hline E & & 5.05 & 3.58 & 4.28 & 3.13 & 94 & 56 & 70 & 55 & 300 & 187 & 217 & 198 \\
\hline$P m+E$ & & 6.13 & 3.35 & 3.89 & 3.63 & 127 & 66 & 62 & 48 & 405 & 220 & 278 & 238 \\
\hline$U C$ & \multirow{5}{*}{7 wks } & 4.19 & 3.89 & & & 2 & 2 & & & 7 & 20 & & \\
\hline $\mathrm{Pm}$ & & 9.93 & 4.68 & & & 211 & 35 & & & 729 & 156 & & \\
\hline E & & 7.33 & 5.85 & & & 113 & 98 & & & 521 & 472 & & \\
\hline$P m+E$ & & 9.41 & 5.13 & & & 188 & 95 & & & 681 & 436 & & \\
\hline$P \min 1 w$ & & 9.90 & 5.61 & & & 184 & 73 & & & 754 & 416 & & \\
\hline UC & \multirow{5}{*}{8 wks } & 6.01 & 4.82 & 0.66 & 0.55 & 4 & 6 & 0 & 1 & 23 & 55 & 0 & 2 \\
\hline $\mathrm{Pm}$ & & 14.65 & 5.82 & 1102 & 1.63 & 300 & 34 & 131 & 22 & 1084 & 269 & 656 & 133 \\
\hline E & & 13.22 & 8.73 & 9.82 & 9.64 & 133 & 70 & 86 & 56 & 1003 & 645 & 317 & 173 \\
\hline$P m+E$ & & 13.38 & 6.62 & 1229 & 7,74 & 206 & 56 & 68 & 42 & 830 & 465 & 469 & 225 \\
\hline$P m 2 w+E$ & & 1298 & 8.95 & & & 268 & 93 & & & 1022 & 444 & & \\
\hline$U C$ & \multirow{5}{*}{10 wks } & 7,93 & 6.51 & 0.80 & 0.64 & 3 & 3 & 2 & 1 & 40 & 51 & 5 & 3 \\
\hline $\mathrm{Pm}$ & & 26.04 & 6.43 & 21.62 & 3.88 & 215 & 27 & 169 & 10 & 1379 & 310 & 808 & 146 \\
\hline$E$ & & 18.67 & 13.68 & 21.37 & 13.58 & 171 & 85 & 71 & 55 & 1168 & 804 & 391 & 296 \\
\hline$P m+E$ & & 25.94 & 16.03 & 21.52 & 12.81 & 207 & 62 & 97 & 46 & 1059 & 706 & 669 & 339 \\
\hline$P m A w+E$ & & 26.25 & 11.58 & & & 255 & 59 & & & 1435 & 305 & & \\
\hline
\end{tabular}

Egypt. J. Soil Sci. 54, No. 3 (2014) 
W: Williams variety. wks: Weeks . E: Reference str. CB 1809. 671: New introduction. UC: Untreated control. Verm: Vermiculite . Pm: Pre-inoculated with str. 123.

In vermiculite medium the growth rate and consequently accumulation of plant biomass was quite different than that obtained by soil treatments for both soybean varieties at 10 weeks except in case of that treatment included P1 671 when inoculated with CB 1809, since the obtained data were much close in both soil and vermiculite. That means that the host plant $\mathrm{P} 1671$ proved to be more promiscuous to rhizobial strain CB 1809 in both used media soil and vermiculite in contrast to the pattern happened with Williams. These data are in agreement with those obtained by Abd El-Maksoud and Keyser (2010). Generally, in contrast to soil treatment Williams was almost equally productive with strain CB 1809 as with strain 123. As clearly seen, P1 671 was much more productive with strain1809 than with strain 123 (13.58 and $3.88 \mathrm{~g} /$ plant, respectively. The reaction between the host and the symbiont still continued even in case of competition between the two strains $(12.81 \mathrm{~g} /$ plant $)$. In other words, the data of competition treatment look like the data of Williams inoculated with strain 123 alone and P1 671 inoculated with CB 1809 alone. In this respect, the data obtained by Kosslak et al. (1983) indicated that interaction which occurred during the early period of infection between soybean host and its microsymbiote are perhaps the most critical for competition among $R$. japonicum strains. The role of the host in determining the outcome of competition among strains was highlighted by the different rate of biomass accumulation for both strains interacted with each host. These results suggested that the early events in infection and nodulation are important in competition among B. japonicum strains.

Regards to the nodule numbers in soil treatment strain USDA 123 initiated a fast start compared to CB 1809 on Williams (61 and 8 nodules, respectively). Also, at 70 DAP the nodule number of CB 1809 on Williams still increasing compared to USDA 123. Context, perhaps CB 1809 is more sensitive to nitrate content of soil (29.06 ppm) which decreased by time through progress in plant growth. In looking at P1 671 in the competition treatment versus CB 1809 alone, the nodule numbers indicate that they probably are due to nodulation by $\mathrm{CB}$ 1809 rather than USDA 123. This has been previously demonstrated by Keyser and Cregan (1987) and Zodor \& Pueppke (1988) however, the occupying nodule analyses by FA procedure will answer this case. Moreover, in the delayed inoculation treatments $(\mathrm{Pm} 2 \mathrm{w}=\mathrm{E}$ and/or $\mathrm{Pm} 4 \mathrm{w}=\mathrm{E})$ the nodule numbers on 671 are more similar to their numbers with $\mathrm{CB} 1809$ alone than with strain USDA 123 alone.

On the other hand, in vermiculite growth medium, the nodule numbers on soybean varieties were lower in most treatments, except those of at earlier stage of plant growth, compared to the corresponding treatments of soil. In single inoculation treatments, nodule number peak (131) was at 56 DAP ( 8 weeks) with Williams which has over 8 times as much as nodules with USDA 123 as did P1 671. As maintained in soil Williams had fewer nodules with CB 1809 than with 123. In the competition treatment most of the 671 nodules are probably from $\mathrm{CB}$ 
1809. These findings are confirmed with obtained by Kosslak and Bohlool (1985) who established that serogroup 123 is poorly competitive in occupying nodules under certain conditions, i.e., 123 to be less competitive than 110 in vermiculite or rhizobia free soil. However, Zodor and Pueppke (1988) found that nodule numbers initially increased at similar rates in soybean plants inoculated with strain 23 and 138 in sterile soil.

The nodule dry weight is closely outcomes from nodule numbers in most cases. In the uninoculated treatments some nodules occurred at 7-10 weeks. This is not expected to interfere with the obtained results in a series matter. Ingeneral, the data showed similar trends as nodule numbers. IN case of soil treatments, it was observed that strain 123 was very restricted on P1 671 compared to Williams, since the nodule weights ranged between $1 / 7: 1 / 5$ those recorded for Williams. Whereas CB 1809 nodulated well on both Williams and P1 671. In the competition treatment the nodule weight for P1 671 were fair similar to those inoculated with CB 1809 alone, a long the plant growth period. In the delayed inoculation treatments, the delay of inoculation with the effective strain CB 1809 resulted in decreasing the nodules on the root of the plant, thus the nodule dry weight of Williams was more pronounced (almost 5/1) compared to those recorded for P1 671.

Regards to vermiculite treatments, in contrast to nodule numbers, nodule biomass appeared to be steadily increasing through 70 DAP. Again, Williams formed more nodule mass with strain 123 than with CB 1809, whereas P1 did the opposite. Also, the nodule weights of competition treatment look similar to data of single inoculation of Williams with strain 123 and /or of P1 671 with CB 1809. Notable differences in soybean nodulation were also observed with other workers, Olsson et. al. (1989) who found that a 7-day delay in inoculation resulted in only $30 \%$ suppression of nodulation. In accordance with our data Kosslak and Bohlool (1984) who stated that the systemic nodule suppression seemed to be related to the host's mechanism of nodule regulation.

Table 2 shows the percentage of the soybean plants Williams and P1 671 in the two grown media soil and vermiculite affected with the inoculation treatment with two different strains USDA 123 and CB 1809. The amount of $\mathrm{N}$ fixed by legume plants depends mainly upon the successful or failure of nodulation process by the effective rhizobial strain. In case of successful nodulation by the compatible effective strain could lead to higher levels of $\mathrm{N}_{2}$ being fixed or a greater portion of total $\mathrm{N}$ from BNF (Keyser and Li, 1992). The variation in $\mathrm{N}$ percentage may not accessible as obvious seen, it differs along the plant growth stage and the accumulative biomass. However, from the first sight it could be observed that the least values of $\mathrm{N} \%$ were recognized in uninoculated treatment (control) due the shortage of $\mathrm{N}$ requirements in both growth media soil and vermiculite. It is logically that $\mathrm{N}$ uptake by plant continuously augments progressively along plant live. Also the $\mathrm{N}_{2}$ fixation process was more successful in soil compared to vermiculite, since the accumulative $\mathrm{N}$ uptake by plant among

Egypt. J. Soil Sci. 54, No. 3 (2014) 
the experiment was more pronounced in all soil treatments corresponding to those of vermiculite as clearly seen in Table 2. Among all treatments it could observed that the quantity of $\mathrm{N}$ uptake by Williams greatly surpassed that by P1 671 particularly that of the pre-inoculated treatment of soil with USDA 123 (more than 6 times). The present data were in compliance with those obtained by Abd El-Maksoud and Keyser (2010) who established that soybean genotype Williams is vigorous to attach with B. japonicum strain USDA 123 , while the introduced P1 671 is restricted to that bacterium but most firmly to nodulate with other different strains (CB 1809). The increasing N uptake by P1 671 which occurred when inoculated with CB 1809 could be ascribed to the good compatibility between this strain and the host. However, the dual inoculation with the two symbionts revealed appreciable quantity of plant $\mathrm{N}$ uptake by the hosts compared to the single inoculation practice in both growth media soil and vermiculite. The delay inoculation treatment in soil at earlier stages of plant growth after 1 and/or 2 weeks did not exhibit any negative effect on $\mathrm{N}$ uptake by P1 671, but when this practice was done after 4 weeks the adverse effect on plant $\mathrm{N}$ uptake certainly verified, since its value sharply decreased from 359.85 to $277.12 \mathrm{mg} / \mathrm{plant}$ with decreasing rate reached to $29 \%$. It appears that the legume plant can distinguish the fate of an infection at a very early stage of plant growth with respect to its potential in establishing the symbiotic nitrogen-fixing state as mentioned by Verma and Nadler (1987).

TABLE 2. Mean of $\mathbf{N} \% \& \mathbf{N}$ content per plant top.

\begin{tabular}{|c|c|c|c|c|c|c|c|c|c|}
\hline \multirow[t]{3}{*}{ Treatment } & \multirow{3}{*}{$\begin{array}{c}\text { Time of } \\
\text { sampling }\end{array}$} & \multicolumn{4}{|c|}{ Soil } & \multicolumn{4}{|c|}{ Vermiculite } \\
\hline & & \multicolumn{2}{|c|}{$\mathbf{N} \%$} & \multicolumn{2}{|c|}{$\begin{array}{l}\text { N-uptake } \\
\text { mg/ plant }\end{array}$} & \multicolumn{2}{|c|}{$\mathbf{N} \%$} & \multicolumn{2}{|c|}{$\begin{array}{l}\text { N-uptake } \\
\text { mg/ plant }\end{array}$} \\
\hline & & Williams & 671 & Williams & 671 & Williams & 671 & Williams & 671 \\
\hline UC & \multirow[t]{4}{*}{4 wks } & 2.40 & 1.68 & 36.16 & 25.28 & 1.65 & 1.17 & 6.35 & 4.51 \\
\hline $\mathrm{Pm}$ & & 2.75 & 1.88 & 37.10 & 27.03 & 3.63 & 1.65 & 27.37 & 6.31 \\
\hline $\mathrm{E}$ & & 2.60 & 1.92 & 35.80 & 25.08 & 3.80 & 4.07 & 29.13 & 29.10 \\
\hline $\mathrm{Pm}+\mathrm{E}$ & & 2.74 & 1.87 & 40.22 & 26.06 & 3.68 & 3.58 & 28.55 & 23.24 \\
\hline UC & \multirow[t]{4}{*}{$6 \mathrm{wks}$} & 1.21 & 0.91 & 45.80 & 33.75 & 1.07 & 1.00 & 6.51 & 4.93 \\
\hline $\mathrm{Pm}$ & & 2.52 & 1.03 & 147.37 & 33.67 & 2.70 & 2.31 & 99.16 & 17.31 \\
\hline $\mathrm{E}$ & & 2.37 & 2.03 & 119.36 & 73.36 & 2.99 & 2.58 & 124.63 & 80.00 \\
\hline $\mathrm{Pm}+\mathrm{E}$ & & 2.77 & 2.15 & 169.74 & 71.69 & 3.11 & 2.46 & 119.86 & 86.35 \\
\hline UC & \multirow[t]{5}{*}{7 wks } & 0.78 & 0.73 & 32.56 & 28.23 & & & & \\
\hline $\mathrm{Pm}$ & & 1.80 & 0.92 & 179.25 & 43.12 & & & & \\
\hline $\mathrm{E}$ & & 2.56 & 2.35 & 187.74 & \begin{tabular}{|l|}
136.75 \\
\end{tabular} & & & & \\
\hline $\mathrm{Pm}+\mathrm{E}$ & & 2.38 & 2.52 & 224.07 & \begin{tabular}{|l|}
130.23 \\
\end{tabular} & & & & \\
\hline Pm1w+E & & 2.39 & 2.31 & 236.04 & 153.60 & & & & \\
\hline $\mathrm{UC}$ & \multirow[t]{5}{*}{8 wks } & 0.87 & 0.81 & 51.35 & 38.61 & 0.90 & 0.72 & 5.82 & 3.90 \\
\hline $\mathrm{Pm}$ & & 2.19 & 1.11 & 322.51 & 64.96 & 1.83 & 1.54 & 198.86 & 25.38 \\
\hline $\mathrm{E}$ & & 2.52 & 2.50 & 332.97 & 220.90 & 2.04 & 2.03 & 197.56 & 194.68 \\
\hline $\mathrm{Pm}+\mathrm{E}$ & & 2.24 & 3.12 & 287.64 & 207.96 & 1.96 & 2.11 & 200.18 & 161.89 \\
\hline $\mathrm{Pm} 2 \mathrm{w}+\mathrm{E}$ & & 2.52 & 2.78 & 323.89 & 246.03 & & & & \\
\hline UC & \multirow[t]{4}{*}{$10 \mathrm{wks}$} & 0.74 & 0.80 & 58.60 & 52.58 & 0.80 & 0.69 & 6.54 & 4.37 \\
\hline $\mathrm{Pm}$ & & 2.37 & 1.42 & 602.86 & 91.08 & 1.63 & 1.48 & 351.53 & 55.13 \\
\hline $\mathrm{E}$ & & 1.89 & 2.69 & 352.13 & 359.85 & 1.77 & 1.81 & 375.26 & 250.13 \\
\hline $\mathrm{Pm}+\mathrm{E}$ & & 2.04 & 1.87 & 524.25 & 298.17 & 1.63 & 2.07 & 351.33 & 264.12 \\
\hline
\end{tabular}




\begin{tabular}{|l|l|l|l|l|l|l|l|l|l|}
\hline Pm4w+E & 1.92 & 2.39 & 497.17 & 277.12 & & & & \\
\hline
\end{tabular}

The data of typing 100 nodules/treatment of soybean plants Williams and p1 671 are presented in Table 3.In the dual inoculation treatment $\mathrm{Pm}+\mathrm{E}$ the nodule typing at 4, 6 and 7 weeks in soil medium exhibited that the majority of Williams nodules $(89-92 \%)$ were occupied with strain USDA 123 whenever CB 1809 existed in few numbers of nodules $(6-8 \%)$. Conversely, the host P1 671 was restricted to USDA 123, since the representative nodules were the ewer compared to the compatible strain CB 1809 was actually the highest existing in its nodules (96 - 100). Similar findings were found by Zodor and Pueppke (1988) who mentioned that early nodulation kinetics of Bradyrhizobium strain cannot be used to predict its success in occupying nodules.

TABLE 3. Nodule typing for rhizobia strain USDA 123 and CB 189.

\begin{tabular}{|c|c|c|c|c|c|c|c|c|c|}
\hline \multirow{4}{*}{\begin{tabular}{|c|}
$\begin{array}{c}\text { Treat- } \\
\text { ment }\end{array}$ \\
Strain \\
\end{tabular}} & \multirow{4}{*}{$\begin{array}{c}\text { Time of } \\
\text { sampling } \\
\text { (week) }\end{array}$} & \multicolumn{4}{|c|}{ soil } & \multicolumn{4}{|c|}{ Vermiculite } \\
\hline & & \multicolumn{4}{|c|}{$\%$} & \multicolumn{4}{|c|}{$\%$} \\
\hline & & \multicolumn{2}{|c|}{ Williams } & \multicolumn{2}{|c|}{ P1 671} & \multicolumn{2}{|c|}{ Williams } & \multicolumn{2}{|c|}{ P1 671} \\
\hline & & 123 & $E$ & 123 & $\mathrm{E}$ & 123 & $\mathrm{E}$ & 123 & $\mathrm{E}$ \\
\hline & 4 & 92 & 6 & 0 & 100 & 43 & 39 & 0 & 100 \\
\hline \multirow[t]{2}{*}{$\mathrm{Pm}+\mathrm{E}$} & 6 & 92 & 8 & 2 & 98 & 80 & 25 & 16 & 86 \\
\hline & 7 & 89 & 8 & 4 & 96 & & & & \\
\hline Pmlwk+E & 7 & 98 & 5 & 4 & 96 & & & & \\
\hline $\mathrm{Pm}+\mathrm{E}$ & 8 & 96 & 3 & 3 & 100 & 62 & 49 & 9 & 93 \\
\hline $\begin{array}{c}\text { Pm2wks + } \\
\text { E }\end{array}$ & 8 & 95 & 3 & 2 & 99 & & & & \\
\hline $\mathrm{Pm}+\mathrm{E}$ & 10 & 96 & 9 & 29 & 70 & 64 & 46 & 16 & 95 \\
\hline $\begin{array}{c}\text { Pm4wks + } \\
\text { E }\end{array}$ & 10 & 89 & 14 & 13 & 89 & & & & \\
\hline
\end{tabular}

Number of 100 nodules were typed for each treatment (25 nodules/replicate).

In vermiculite medium the same trend in soil was noticed but different ratios were obtained, however the strain 123 was the preferable to Williams and CB 1809 to P1 671. In this respect, Verma and Nadler (1987) stated that the first step in the development of the root nodule symbiosis is the mutual recognition by the two partners - a process which is rather specific. In the delay inoculated treatment Pm 1 week + E the pre-exposure of strain 123 to soybean roots increased the nodule number occupancy of the strain to $98 \%$, hence the nodule occupancy with E strain apparently decreased $5 \%$, whereas, it was the highly distinguished with P1 671. In the fourth stage after 8 weeks the dual inoculation of the symbionts did not appear any remarkable variations in both soil and vermiculite. These data are in agreement with obtained by Ham (1980) who stated that the host plays an important role in determining which strain succeeds in occupying the majority of nodules on root of legume plant. On contrast, Kosslak et al. (1983) reported that the pre- exposure of soybean roots to a poor 
competitive strain of $R$. japnicum results in a significant increase in nodule occupancy by that strain.

In the second delay inoculation treatment Pm 2 weeks $+\mathrm{E}$ in soil, 56 DAP, although the exposure of the host P1 671 to strain USDA 12315 days before inclusion the strain however, it did not exceed its nodulation occupancy ratio than $2 \%$, whereas $99 \%$ of total nodules were infected with E strain. After 10 weeks of dual inoculation treatment in the soil and vermiculite, no obvious variation than previous tendency were obtained, except a little increase of nodule number invested with USDA 123 on roots of P1 671 (29\%) followed by parallel decrease in nodule numbers occupied by E strain $(70 \%)$. At the end of ten weeks, delay inoculation treatment $\mathrm{Pm} 4$ weeks $+\mathrm{E}$ in soil exhibited some variations in nodule occupying ratio of both strains USDA 123 and E for both Williams and P1 671. The strain 123 existed in most of Williams's nodules (89), whereas not much nodule numbers were occupied by E strain $(14 \%)$. On the other hand, the opposite was found by the two strains on the host P1 671. In contrary to that Kosslak et al. (1983) established that the majority of the nodules formed on the mature plant were initiated by the strain to which the host was expressed and this occurred whether the primary inoculums was an effective or ineffective strain. These results indicate that indigenous non-effective strain could be restricted through selection of the suitable host plant and inoculation with preferable Rhizobium strain at the early stage of plant growth.

\section{References}

Abd El-Maksoud, H.K. and Keyser, H.H. (2010) Restriction specificity of some soybean genotypes to Bradyrhizobium japonicum serogroups. World Academy of Science and Technology 71: 418 - 421.

Bauer, W.D. (1981) Infection of legumes by rhizobia. Ann. Ref. Plant Physiol. 32: 407 449.

Bohlool, B.B. and Schmidt, E.L. (1980) The immunofluorescebce Approach in Microbial Ecology 4: 203 - 241.

Broughton, W.J. and Delworth, M.J. (1971) Control of leghemoglobin synthesis in snake beans. Biochem. J. 125: 1075 -1080.

Cregan, P.B. and Keyser, H.H. (1986) Host restricition of nodulation by Bradyrhizobium japonicum strain USDA 123 in soybean. Crop Sci. 26: 911 - 916.

Diatloff, A. and Brockwell, J. (1976) Symbiotic properties of Rhizobium japonicum and competitive success in nodulation of two Glycine max cultivars by effective and ineffective strains. Aust. J. Exp. Agric. Anim. Husb. 9: 357 - 360.

Dowling, D.N. and Broughton, W.J. (1986) Competition for nodulation of legumes. Annual Review of Microbiology 40: 131 - 157. 
Franco, A.A. and Vinicent, J.H. (1976) Competition among rhizobial strains for the colonization and nodulation of two tropical legumes. Plant and Soil 45: 27 - 48.

Ham, G.E. (1980) Interaction of Glycine max. and Rhizobium japonicum. In: "Advances in Legume Science”, R.J. Summerfield and A.H. Bunting (Ed.), pp. 289 - 296, Royal Botinical Gardens, Kew, UK.

Heron, D.S. and Pueppke, S.G. (1987) Regulation of nodulation in the soybeanRhizobium symbiosis strain and cultivar variability. Plant Physiol. 84: 1391 - 1396.

Keyser, H.H. and Cregan, P.B. (1987) Nodulation and competition for nodulation of selected soybean genotypes among Bradyrhizobium japonicum serogroup 123 isolates. Appl. Environ. Microbiol. 53: 2631 - 2635.

Keyser, H.H. and Li, F. (1992) Potential for increasing biological nitrogen fixation in soybean. Plant and Soil 141: 119 - 135.

Kosslak, R.M. and Bohlool, B.B. (1984) Suppression of nodule development of one side of a split-root system of soybeans caused by prior inoculation of the other side. Plant Physiol. 75: $125-130$.

Kosslak, R.M. and Bohlool, B.B. (1985) Influence of environmental factors on interstrain competition in Rhizobium japonicum. Appl. Environ. Microbiol. 49: 1128-1133.

Kosslak, R.M., Bohlool, B.B., Dowdle, S. and Sadowsky, M.J. (1983) Competition of Rhizobium japonicum strains in early stages of soybean nodulation. Appl. Environ. Microbiol. 46: $870-873$.

May, S.N. and Bohlool, B.B. (1983). Competition among Rhizobium leguminsarum strains for nodulation of lentils (Lens esculenta). Appl. Environ. Microbiol. 44: 960 - 965.

Olsson, J.E., Nakao, P., Bohlool, B.B. and Gresshoff, P.M. (1989) Lack of systemic suppression of nodulation in split root system of supernodulating soybean ( Glycine max L. Merr.) mutants. Plant Physiol. 90 : 1347 - 1352.

Somasegaran, P. and Hoben, H.J. (1985) "Methods in Legume-Rhizobium Technology", NifTAL Handbook, Hawaii Univ., USA.

Swelim, D.M., Kuykendall, L.D., Hashem, F.M., Abdel-Wahab, S.M. and Hegazy, N.I. (1996) Competitiveness of Rhizobium sp. \{Leucaena leucocephala (lam.) Dewit\} strains and their genetically marked derivatives. Letters in Applied Microbiology 22: $443-447$.

Trinick, M.J. (1982) Competition between rhizobial strains for nodulation. In : "Nitrogen Fixation in Legumes", J.M. Vincent (Ed.), pp. 229- 238, Sydney, Academic Press.

Verma, D.P.S. and Nadler, K. (1987) Legume-Rhizobium-Symbiosis: Host's Point of View. Mich. USA. Plant Gene Research: 58 -93.

Zodor, R.E. and Pueppke, S.G. (1988) Early infection and competition for nodulation of soybean by Bradyrhizobium japonicum 123 and 138. Appl.Environ. Microbiol. 54 (8): $1996-2002$.

Egypt. J. Soil Sci. 54, No. 3 (2014) 
(Received 4/12/2013; accepted 17/8/2014)

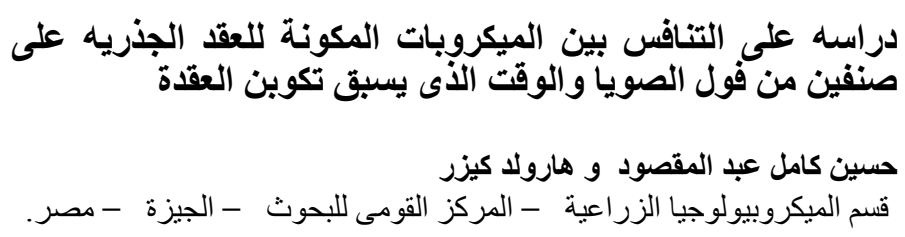

تم اجراء تجربة اصص لتقدير الوقت اللازم لبدء تكوين العقد الجذرية وكذلك

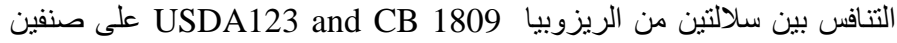

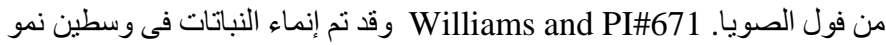
Vermiculite

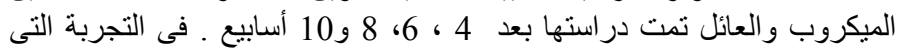

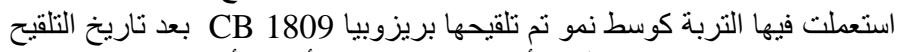

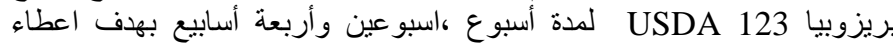

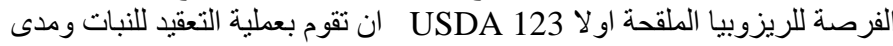

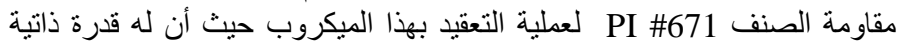

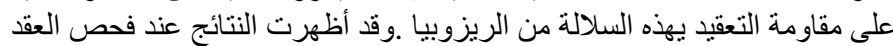

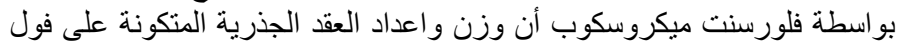

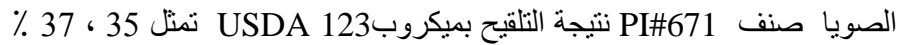
على التو الى من مجموع العقد الجذرية على الجذور ، اما باقي العقد فكانت محتويه

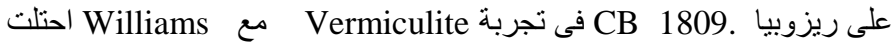

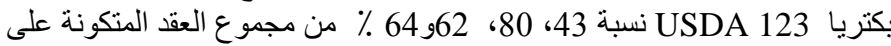

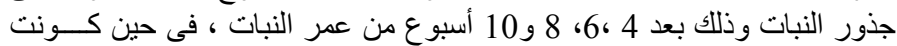

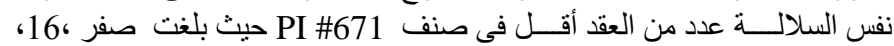
9و16 \% بنفس المدد المذكورة سابقا.

فى التجربة المستعمل فيها التربة كوسط نمو اللنبات كونت سلالة الريزوبيا

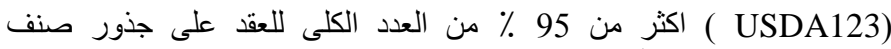

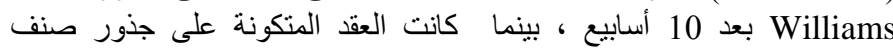
PI\#671 لنفس السلالة تقل عن نسبة 29 ٪ 29

في التجربة التى تم التلقيح فيها بميكروب CB1809 متأخرا عن التلقيح ل

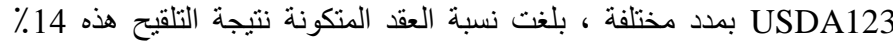

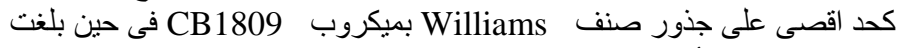
هذه النسبة 89 ٪ أو اكثر على جذور صنف

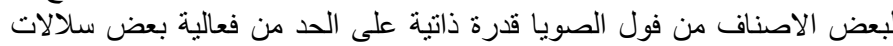

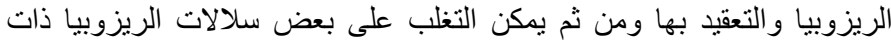

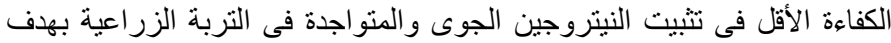

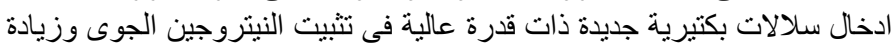

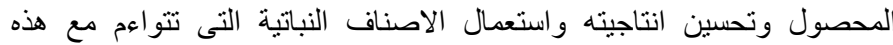
الميكروبات . 
H.K. ABD EL-MAKSOUD AND H.H. KEYSER

Egypt. J. Soil Sci. 54, No. 3 (2014) 